\title{
Synthesis and structural characterization using the Rietveld method of the quaternary compound $\mathrm{CuAlGeSe}{ }_{4}^{\dagger}$
}

\author{
Gerzon E. Delgado ${ }^{a, *}$ and Miguel Quintero ${ }^{b}$ \\ ${ }^{a}$ Laboratorio de Cristalografía, Departamento de Química, \\ Facultad de Ciencias, Universidad de Los Andes, Mérida 5101, Venezuela. \\ *e-mail: gerzon@ula.ve \\ ${ }^{b}$ Centro de Estudios de Semiconductores, Departamento de Física, \\ Facultad de Ciencias, Universidad de Los Andes, Mérida 5101, Venezuela. \\ ${ }^{\dagger}$ Dedicated to the memory of Professor Santos Adán López-Rivera.
}

Received 5 July 2021; accepted 2 August 2021

Sample of the quaternary phase $\mathrm{CuAlGeSe}$, a part of I-III-IV- $\square-\mathrm{VI}_{4}$ semiconductor system, was synthesized by the melt and annealing technique and analyzed using $\mathrm{X}$-ray powder diffraction data. The indexing and refinement of the pattern indicate that this compound crystallizes in the tetragonal system, space group $I \overline{4}\left(\mathrm{~N}^{\circ} 82\right)$ with unit cell parameters: $a=5.5646(3) \AA, c=10.682(2) \AA, V=330.77(5) \AA^{3}$. The space group was established from a cationic and anionic distribution analysis in the tetragonal space groups: $I \overline{4} 2 \mathrm{~d}\left(\mathrm{~N}^{\circ} 122\right), I \overline{4} 22 \mathrm{~m}\left(\mathrm{~N}^{\circ}\right.$ $121)$, and $I \overline{4} 2\left(\mathrm{~N}^{\circ} 82\right)$, for an ordered structure in this material. The Rietveld refinement, performed with the starting model: $\mathrm{Cu} 2 c, \mathrm{Al} 2 b$, Ge $2 d, \square 2 a$, and Se $8 g$, converged to $R_{\exp }=7.2 \%, R_{P}=7.4 \%, R_{w p}=9.6 \%$, and $\chi^{2}=1.7$.

Keywords: Chalcogenide; powder X-ray diffraction; crystal structure.

DOI: https://doi.org/10.31349/RevMexFis.68.020501

\section{Introduction}

Copper quaternary chalcogenide semiconductors are still of great interest due to their potential application as magnetooptic and thermoelectric materials, solar-cell absorbers, and photocatalysts for solar water splitting [1-4]. In general, this type of materials belongs to the families of normal semiconductor compounds with composition $\mathrm{I}_{2}-\mathrm{II}-\mathrm{IV}-\mathrm{VI}_{4}$, an equal number of cations and anions, and two good examples are $\mathrm{Cu}_{2} \mathrm{ZnSnS}_{4}$ and $\mathrm{Cu}_{2} \mathrm{ZnSnSe}_{4}$ which are naturally abundant and have shown conversion efficiencies as high as 10\% [5]. These compounds adopt one of two well-defined sphalerite or wurtzite derivatives structures [6,7].

There are also defect quaternary compounds of the type I-III-IV-VI ${ }_{4}$, fewer cations than anions, which possess photoelectric and photo-luminescent properties that make them recent interesting from the point of view of their application as optoelectronic materials [8-10]. This family I-III-IV-VI, better written as I-III-IV- $\square-V_{4}$ were $\square$, denote the cationic vacancy, fulfill the rules of formation of adamantane compounds, and belongs to the defect semiconductor compound families [11]. However, for these materials, their crystalline structures have not been unambiguously established, due to the difficulty in the distribution of the cations in the available crystallographic positions (Wyckoff sites). Several members of this family have been structurally studied using photographic films taken at a Debye-Scherrer camera [12-14], founds unit cell parameters with tetragonal symmetry. However, in any case, were specified space group or structural details.
In these earlier studies, a defect chalcopyrite-type was assigned using a model where the disorderly cation I shared position with the vacancy while the cations III and IV share another atomic site. This model can be described as (Cu- $\square$ )(IIIIV)Se $\mathrm{Se}_{4}$ and was also used to describe the crystal structure of the quaternary compounds $\mathrm{CuGaGeSe}_{4}$ and $\mathrm{CuInGeSe} 4$ [15] in the tetragonal space group $I \overline{4} 2 \mathrm{~d}$ where the cationic sub-lattice is disordered. Later, the crystal structure of the sulfide compound $\mathrm{CuInSnS}_{4}$ was described in the tetragonal space group $I \overline{4}$ but also with a disordered distribution of their cations [16]. In this work, a detailed structural analysis for the compound $\mathrm{CuAlGeSe}$, was performed using X-ray powder diffraction, aiming to derive an ordered model that explains all the diffraction peaks in the powder pattern and to refine it employing the Rietveld method. Bond lengths derived from the refined results were used for the bond-valence sum (BVS) calculations $[17,18]$, which allowed to verify the chemical sense of the structural model.

\section{Experimental}

The sample of $\mathrm{CuAlGeSe}$ was synthesized, through reaction in the solid-state of the constituent elements, $\mathrm{Cu}, \mathrm{Al}, \mathrm{Ge}$, and Se, until reaching their fusion. The mixture was introduced into an evacuated quartz ampoule and brought to a horizontal two-zone furnace. The mixture was slowly heated up to $500^{\circ} \mathrm{C}$ in 3 days. It was kept at this temperature for three more days. Then, it was heated at $1100^{\circ} \mathrm{C}$ and remained at this temperature for 2 hours. Then, the reacted mixture was annealed at $500^{\circ} \mathrm{C}$ for a month. Finally, the sample was cooled to room temperature in about a day. 
Chemical analysis was carried out with a Hitachi S2500 scanning electron microscope (SEM) equipped with a Kevex EDX accessory. Three different regions of the ingot were scanned, and the average atomic percentages are $\mathrm{Cu}$ (17.52\%), Al (15.34\%), Ge (14.32\%), and Se (52.82\%). The error in the standardless analysis was around $5 \%$. These values are in good agreement with the ideal composition 1:1:1:4.

A small quantity of the sample was ground mechanically in an agate mortar and pestle. The resulting fine powder was mounted on a flat zero-background holder covered with a thin layer of grease. The X-ray powder diffraction data were collected at room temperature, in $\theta / 2 \theta$ reflection mode using a Siemens D5005 diffractometer equipped with an X-ray tube $\left(\mathrm{CuK}_{\alpha 1}\right.$ radiation: $\left.\lambda=1.54059 \AA ; 40 \mathrm{kV}, 30 \mathrm{~mA}\right)$ using a $\mathrm{Ge}<111>$ incident beam monochromator. Fix scatter of $0.1 \mathrm{~mm}$, divergence slits of $1 \mathrm{~mm}$, and a $0.1 \mathrm{~mm}$ receiving slit was used. The specimen was scanned in the $2 \theta$ range of $10-100^{\circ}$, the scan step was $0.02^{\circ}$, and the time of counting in every step was $46 \mathrm{~s}$. The sample was rotated on its axis during exposure with a speed of 15 r.p.m. to avoid preferred orientation. Quartz was used as an external standard. The Bruker analytical software was used to establish the positions of the peaks.

\section{Results and discussion}

The indexing of the X-ray powder diffraction was performed using the program DICVOL [19]. The first 20 peak positions were used as input data. A solution with a tetragonal cell was given by the program. The following parameters were obtained: $a=5.5681(1) \AA, c=10.692(2) \AA$. The systematic absences study ( $h k l: h+k+l=2 n)$ indicated an $I$-type cell and the possible space groups $I \overline{4} 2 \mathrm{~d}\left(\mathrm{~N}^{\circ} 122\right), I \overline{4} 2 \mathrm{~m}\left(\mathrm{~N}^{\circ}\right.$ $121)$, and $I \overline{4}\left(\mathrm{~N}^{\circ} 82\right)$.

To obtain the initial structural model before refining by the Rietveld method [20], several models were derived by permuting the cations in the available Wyckoff positions for the three space groups with $\mathrm{Z}=2$. Only in the space group $I \overline{4}$ was it possible to accommodate all three cations and vacancy with a multiplicity of 2 in the atomic site maintaining an ordered distribution.

Therefore, different models were prepared in this space group alternating the position of the cations and vacancies in the available atomic sites: $2 a(0,0,0), 2 b(0,0,1 / 2)$, $2 c(0,1 / 2,1 / 4)$, and $2 d(0,1 / 2,3 / 4)$, with the anion Se in the atomic positions $8 \mathrm{~g}(x, y, z)$ with $x \approx 1 / 4, y \approx 1 / 4$, $z \approx 1 / 8$. The better refinement results were those where $\mathrm{Cu}^{1+}$ cation was placed in the Wyckoff site $2 c: 0,1 / 2,1 / 4$. Table I shows the six better models tested against the diffraction data employing the Rietveld method.

The Rietveld refinement of the whole diffraction pattern was carried out using the FULLPROF program [21]. The atomic coordinates of the different models were used as the initial models for the Rietveld refinements. The angular dependence of the peak full width at half maximum (FWHM) was described by the Caglioti formula [22]. Peak shapes were described by the parameterized Thompson-CoxHastings pseudo-Voigt profile function [23]. The background variation was described by a polynomial with six coefficients. The thermal motion of the atoms was described by one overall isotropic temperature factor. From the figures of merit $\mathbf{R}_{p}$, $\mathbf{R}_{w p}$ and $\chi^{2}$, it was inferred that the best model is number 1 . The results of the Rietveld refinement for model 1 are summarized in Table II. Figure 1 shows the observed, calculated, and difference profile for the final cycle of Rietveld refinement.

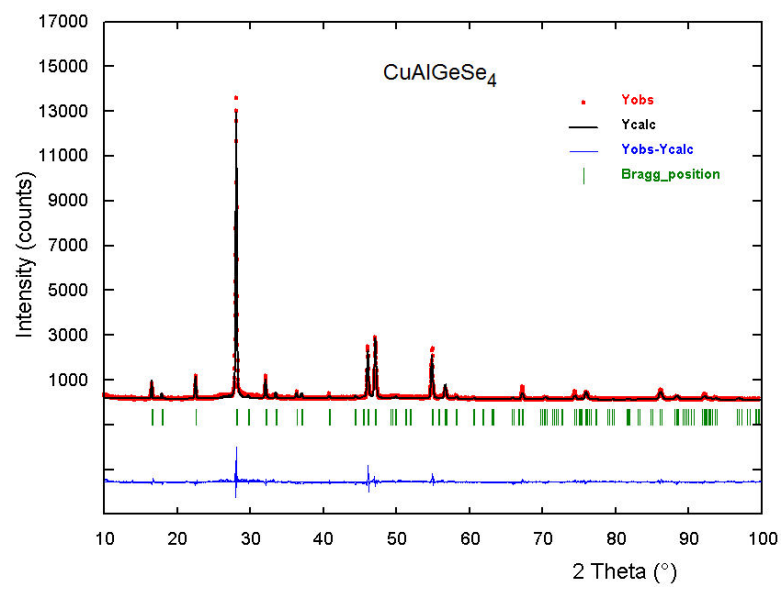

FIGURE 1. Rietveld refinement plot for $\mathrm{CuAlGeSe}_{4}$. The lower trace is the difference curve between observed and calculated patterns.

TABLE I. Models employed in the Rietveld refinement of $\mathrm{CuAlGeSe}_{4}$.

\begin{tabular}{ccccccccc}
\hline Model & $(2 c)$ & $(2 b)$ & $(2 d)$ & $(2 a)$ & $(8 g)$ & $\mathrm{R}_{p}$ & $\mathrm{R}_{w p}$ & $\chi^{2}$ \\
\hline & $0,1 / 2,1 / 4$ & $0,0,1 / 2$ & $0,1 / 2,3 / 4$ & $0,0,0$ & $x, y, z$ & & & \\
1 & $\mathrm{Cu}$ & $\mathrm{Al}$ & $\mathrm{Ge}$ & $\square$ & $\mathrm{Se}$ & 7.4 & 9.6 \\
2 & $\mathrm{Cu}$ & $\mathrm{Al}$ & $\square$ & $\mathrm{Ge}$ & $\mathrm{Se}$ & 10.7 & 17.0 \\
3 & $\mathrm{Cu}$ & $\mathrm{Ge}$ & $\mathrm{Al}$ & $\square$ & $\mathrm{Se}$ & 8.4 & 11.1 & 3.7 \\
4 & $\mathrm{Cu}$ & $\square$ & $\mathrm{Al}$ & $\mathrm{Ge}$ & $\mathrm{Se}$ & 30.8 & 47.2 & 58.3 \\
5 & $\mathrm{Cu}$ & $\mathrm{Ge}$ & $\square$ & $\mathrm{Al}$ & $\mathrm{Se}$ & 12.3 & 18.5 \\
6 & $\mathrm{Cu}$ & $\square$ & $\mathrm{Ge}$ & $\mathrm{Al}$ & $\mathrm{Se}$ & 11.5 & 18.3 & 8.83 \\
\hline
\end{tabular}

$\mathrm{R}_{\exp }=100\left[(N-P+C) / \sum_{w}\left(y_{\mathrm{obs}}^{2}\right)\right]^{1 / 2} \mathrm{R}_{p}=100 \sum\left|y_{\mathrm{obs}}-y_{\text {calc }}\right| / \sum\left|y_{\mathrm{obs}}\right| \chi^{2}=\left[R_{w p}^{2} / R_{\text {exp }}^{2}\right] \mathbf{R}_{w p}=100\left[\sum_{w}\left|y_{\mathrm{obs}}-y_{\text {calc }}\right|^{2} / \sum_{w}\left|y_{\mathrm{obs}}\right|^{2}\right]^{1 / 2}$ $N-P+C$ is the number of degrees of freedom. 
TABLE II. Atomic coordinates, isotropic temperature factors and geometric parameters $\left(\AA{ }^{\circ}{ }^{\circ}\right)$ for $\mathrm{CuAlGeSe}_{4}$.

\begin{tabular}{|c|c|c|c|c|c|c|c|}
\hline \multicolumn{8}{|c|}{$\begin{array}{c}\text { Space group } I \overline{4}\left(\mathrm{~N}^{\circ} 82\right), \mathrm{Z}=2, a=5.5646(3) \AA, \quad c=10.682(2) \AA, V=330.77(5) \AA^{3} \\
\left(\mathrm{R}_{\exp }=7.2 \%, \mathrm{R}_{P}=7.4 \%, \mathrm{R}_{w p}=9.6 \%, \chi^{2}=1.7\right)\end{array}$} \\
\hline Atom & Ox. & Wyckoff & $x$ & $y$ & $z$ & foc & $\mathrm{B}\left(\AA^{2}\right)$ \\
\hline $\mathrm{Cu}$ & +1 & $2 c$ & 0 & $1 / 2$ & $1 / 4$ & 1 & $0.4(4)$ \\
\hline $\mathrm{Al}$ & +3 & $2 b$ & 0 & 0 & $1 / 2$ & 1 & $0.4(4)$ \\
\hline $\mathrm{Ge}$ & +4 & $2 d$ & 0 & $1 / 2$ & $3 / 4$ & 1 & $0.4(4)$ \\
\hline$\square$ & & $2 a$ & 0 & 0 & 0 & 1 & $0.4(4)$ \\
\hline $\mathrm{Se}$ & -2 & $8 g$ & $0.2495(6)$ & $0.2423(4)$ & $0.1214(3)$ & 1 & $0.4(4)$ \\
\hline \multicolumn{2}{|c|}{$\mathrm{Cu}-\mathrm{Se}$} & $2.421(3)$ & \multicolumn{2}{|c|}{$\mathrm{Al}-\mathrm{Se}^{(i)}$} & $2.382(3)$ & $\mathrm{Ge}-\mathrm{Se}^{(i i)}$ & $2.365(3)$ \\
\hline
\end{tabular}

Symmetry codes: ${ }^{(i)} 0.5-y,-0.5+x, 0.5-z ;{ }^{(i i)} 0.5-x, 0.5-y, 0.5+z$.

TABLE III. Bond valence sum (BVS) calculations for $\mathrm{CuAlGeSe}_{4}$.

\begin{tabular}{cccccc}
\hline & $\mathrm{Cu}$ & $\mathrm{Al}$ & $\mathrm{Ge}$ & $\mathrm{Vi}$ & $\begin{array}{c}\text { Formal } \\
\text { oxidation state }\end{array}$ \\
\hline $\mathrm{Se}$ & 0.338 & 0.739 & 0.960 & 2.04 & 2 \\
$\mathrm{xi}$ & 1.35 & $\mathrm{x} 4$ & $\mathrm{x} 4$ & 3.84 & \\
Formal & 1 & 2.96 & 4 & \\
oxidation state & & 3 & & \\
\hline
\end{tabular}

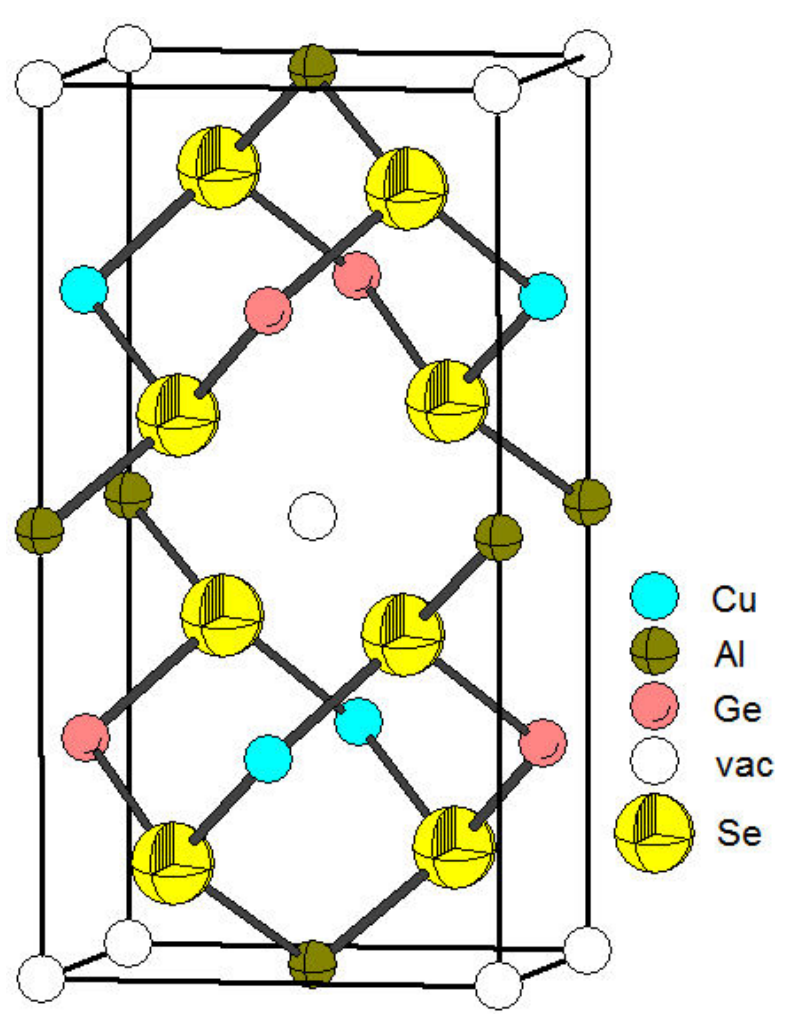

FIGURE 2. Unit cell diagram for $\mathrm{CuAlGeSe}_{4}$ showing the atomic distribution.

On the other hand, the entire pattern was reviewed utilizing the program NBS*AIDS [24] and the powder X-ray diffraction pattern was deposited in the ICDD-PDF with the code PDF-52-1024 [25].
$\mathrm{CuAlGeSe}_{4}$ is a defect adamantane-structure compound [11]. In this structure, each $\mathrm{Se}$ atom is coordinated by four cations [one $\mathrm{Cu}$, one $\mathrm{Al}$, one $\mathrm{Ge}$, and one vacancy. In the same way, each cation is tetrahedrally bonded to four anions. The tetrahedra containing the $\mathrm{Cu}$ atoms [mean Se... Se distance 3.96(2) $\AA$ ] are lightly smaller than those containing the $\mathrm{Al}$ atoms [means Se...Se distance 4.02(1) $\AA$ ], and Ge atoms [mean Se... Se distance 4.24(1) ̊] respectively. Figure 2 shows the unit cell diagram of the $\mathrm{CuAlGeSe}_{4}$ structure where is possible to observe the tetrahedral environment around each of the atoms in the structure.

The $\mathrm{Cu}-\mathrm{Se}$ distance $[2.421(3) \AA]$ is in good agreement with those observed in other adamantane structure compounds as for example the ternaries chalcogenide $\mathrm{CuInSe}_{2}(2.432 \AA)$ [27], $\mathrm{Cu}_{2} \mathrm{SiSe}_{3}$ (2.423 $\AA$ average) [28], $\mathrm{Cu}_{2} \mathrm{SnSe}_{3}$ (2.415 $\AA$ average) [29], and the quaternary compounds $\mathrm{Cu}_{2} \mathrm{CdGeSe}_{4}\left(2.410 \AA\right.$ ) [30], $\mathrm{Cu}_{2} \mathrm{CdSnSe}_{4}(2.427$

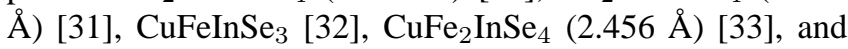
$\mathrm{Cu}_{2} \mathrm{FeIn}_{2} \mathrm{Se}_{5}$ (2.431 $\AA$ ) [34]. The Al-Se distance [2.382(3) $\AA$ ] compares well also with those observed in compounds as $\mathrm{CdAl}_{2} \mathrm{Se}_{4}$ (2.387 $\AA$ average) [35] and $\mathrm{HgAl}_{2} \mathrm{Se}_{4}$ (2.392 $\AA$ ) [36]. The Ge-Se [2.375(3) $\AA$ ] is also in good agreement with similar distances in $\mathrm{Cu}_{2} \mathrm{CdGeSe}_{4}$ [30], and $\mathrm{Cu}_{2} \mathrm{Cd}_{0.5} \mathrm{Mn}_{0.5} \mathrm{GeSe}_{4}$ [37]. The structural model was confirmed by analysis of the interatomic distances using the Bond Valence Sum (BVS) formula founded on bond-strength examination $[17,18]$. These results are shown in Table III and are very close with the expected formal oxidation state of the cations $\mathrm{Cu}^{1+}, \mathrm{Al}^{3+}, \mathrm{Ge}^{4+}$, and the anion $\mathrm{Se}^{2-}$. 


\section{Conclusions}

The crystal structure of the quaternary chalcogenide $\mathrm{CuAlGeSe}_{4}$ was established by an analysis of the cation distribution and the subsequent Rietveld refinement of the better model. This material crystallizes in the tetragonal space group $I \overline{4}\left(\mathrm{~N}^{\circ} 82\right)$, unit cell parameters: $a=5.5646(3) \AA$, $c=10.682(2) \AA, V=330.77(5) \AA^{3}$, with the following Wyckoff site atomic distribution: $\mathrm{Cu}$ in $2 c(0,1 / 2,1 / 4), \mathrm{Al}$ in $2 b(0,0,1 /)$, Ge in $2 d(0,1 / 2,3 / 4), \square$ in $2 a(0,0,0)$, and $\mathrm{Se}$ in $8 g(\mathrm{x}, \mathrm{y}, \mathrm{z})$. This atomic distribution corresponds to an ordered fashion of all cations and anions in the crystal structure. The chemical structural model was confirmed by analysis of the interatomic distances using the Bond Valence Sum (BVS) formula.

\section{Acknowledgments}

This work was supported by CDCHT-ULA, and CONICIT Grant LAB-97000821.
1. S. Chen et al., Wurtzite-derived polytypes of kesterite and stannite quaternary chalcogenide semiconductors, Phys. Rev. B 82 (2010) 195203. http://dx.doi.org/10.1103/ PhysRevB.82.195203

2. H. Katagir, Development of CZTS-based thin film solar cells, Thin Solid Films 517 (2009) 2455. https : / / doi . org/10. $1016 / j . t s f .2008 .11 .002$.

3. C. Coughlan, Compound copper chalcogenide nanocrystals, Chem. Rev. 117 (2017) 5865. https://doi.org/10. $1021 / a c s . c h e m r e v \cdot 6 b 00376$

4. P. Kush and S. Deka, Multifunctional copper-based quaternary chalcogenide semiconductors toward state-of-the-art energy applications, Chem. Nano. Mat 5 (2019) 373. https: //doi.org/10.1002/cnma.201800321

5. A. Walsh, S. Chen, S. Wei, X. Gong, Kesterite thin-film solar cells: Advances in materials modelling of $\mathrm{Cu}_{2} \mathrm{ZnSnS}_{4}$, Adv. Energ. Mater. 2 (2012) 400. https : //doi.org/10. 1002 /aenm.201100630

6. W. Chen et al., Wurtzite-derived polytypes of kesterite and stannite quaternary chalcogenide semiconductors. Phys. Rev. B 82 (2010) 195203. https://doi.org/10.1103/ PhysRevB.82.195203

7. G. E. Delgado, and V. Sagredo, Synthesis and crystal structure of the quaternary semiconductor $\mathrm{Cu}_{2} \mathrm{NiGeS}_{4}$, a new stannitetype compound, Rev. Mex. Fis. 65 (2019) 355. https:// doi.org/10.31349/revmexfis.65.355

8. K. Shen, X. Zhang, H. Lu, and Z. Jiao, Numerical study of the defect adamantine compound $\mathrm{CuGaGeSe}_{4}$, Mol. Phys. 116 (2018) 1551.https://doi.org/10.1080/00268976. 2018.1433338

9. K. Shen, H. Lu, X. Zhang, and Z. Jiao, Numerical study of the electronic structure, elastic and optical properties of defect quaternary semiconductor $\mathrm{CuGaSnSe}_{4}$, Results Phys. 9 (2018) 49. https://doi.org/10.1016/j.rinp.2018.02. 004 .

10. A. S. Hassanien, H. R. Alamri, and I. M. El Radaf, Impact of film thickness on optical properties and optoelectrical parameters of novel $\mathrm{CuGaGeSe} 4$ thin films synthesized by electron beam deposition, Opt. Quantum Electron. 52 (2020) 335. https://doi.org/10.1007/ s11082-020-02448-9
11. E. Parthé, Wurtzite and Sphalerite Structures, in Intermetallic Compounds, edited by J. H. Westbrook and R. L. Fleischer, Vol. 1 (John Wiley and Sons, Chichester, 1995).

12. O. H. Hughes, J. C. Woolley, S. A. López-Rivera, and B. R. Pamplin, Quaternary adamantine selenides and tellurides of the form I III IV VI 4 , Solid State Commun. 35 (1980) 573. https : //doi.org/10.1016/0038-1098(80) 90585-2

13. J. C. Woolley, R. G. Goodchild, O. H. Hughes, S. A. LópezRivera, and B. R. Pamplin, Quaternary defect chalcopyrite compounds I III IV VI 4 , Jpn. J. Appl. Phys. 19 (1980) 145. https://doi.org/10.7567/JJAPS.19S3.145

14. R. G. Goodchild, O. H. Hughes, and J. C. Woolley, Crystal structure of I-III-IV-Se ${ }_{4}$ compounds, Phys. Status Solidi (a), 68 (1981) 239. https://doi.org/10.1002/pssa. 2210680132

15. H. Matsushita, T. Maeda, A. Katsui, and T. Takizawa, J. Cryst. Growth 208 (2000) 416. https://doi.org/10.1016/ S0022-0248(99)00468-6

16. G. P. Gorgut et al., Synthesis and structural properties of $\mathrm{CuInGeS}_{4}$, J. Cryst. Growth 324 (2011) 212. https : / / doi . org/10.1016/j.jcrysgro.2011.02.0

17. I. D. Brown and D. Altermatt, Bond-valence parameters obtained from a systematic analysis of the Inorganic Crystal Structure Database, Acta Cryst. B 41 (1985) 244, https: //doi.org/10.1107/S0108768185002063

18. N. E. Brese and M. O'Keeffe, Bond-valence parameters for solids, Acta Cryst. B 47 (1991) 192, https://doi.org/ $10.1107 / \mathrm{S} 0108768190011041$

19. A. Boultif and D. Louër, Powder pattern indexing with the dichotomy method, J. Appl. Cryst. 37 (2004) 724, https: //doi.org/10.1107/S0021889804014876

20. H. M. Rietveld, A profile refinement method for nuclear and magnetic structures, J. Appl. Cryst. 2 (1969) 65, https: //doi.org/10.1107/S0021889869006558

21. J. Rodríguez-Carvajal, Recent advances in magnetic structure determination by neutron powder diffraction, Phys. B 192 (1993) 55, https://doi.org/10.1016/ 0921-4526(93) 90108-I.

22. G. Caglioti, A. Paoletti, and F. P. Ricci, Choice of collimators for a crystal spectrometer for neutron diffraction, $\mathrm{Nucl}$. Instrum. 3 (1958) 223, https://doi.org/10.1016/ 0369-643X(58) 90029-X 
23. P. Thompson, D. E. Cox, and J. B. Hastings, Rietveld refinement of Debye-Scherrer synchrotron X-ray data from $\mathrm{Al}_{2} \mathrm{O}_{3}, J$. Appl. Cryst. 20 (1987) 79, https: //doi.org/10.1107/ S0021889887087090

24. A. D. Mighell, C. R. Hubbard, and J. K. Stalick, NBS*AIDS: NBS (USA), Tech. Note 11411981.

25. ICDD-PDF, International Centre for Diffraction Data-Powder Diffraction File (Set 1-65), 12 Campus Boulevard, Newtown Square, PA, USA (2019).

26. K. S. Knight, The crystal structures of $\mathrm{CuInSe}_{2}$ and $\mathrm{CuInTe}_{2}$, Mater. Res. Bull. 27 (1992) 161, https://doi.org/ 101016/0025-5408(92)90209-I

27. X. A. Chen, H. Wada, A. Sato, and H. Nozaki, Synthesis, structure, and electronic properties of $\mathrm{Cu}_{2} \mathrm{SiQ}_{3}(\mathrm{Q}=\mathrm{S}, \mathrm{Se}), J . A l$ loys Comp. 290 (1999) 91. https : //doi.org/10.1016/ S0925-8388(99) 00208-X

28. G. E. Delgado, A. J. Mora, G. Marcano, and C. Rincón, Crystal structure refinement of the semiconducting compound $\mathrm{Cu} 2 \mathrm{SnSe} 3$ from X-ray powder diffraction data, Mater. Res. Bull. 38 (2003) 1949. https://doi.org/10.1016/j. materresbull.2003.09.017

29. L. D. Gulay, Ya. E. Romanyuk, and O. V. Parasyuk, Crystal structures of low-and high-temperature modifications of $\mathrm{Cu}_{2} \mathrm{CdGeSe}_{4}$, J. Alloys Comp. 347 (2002) 193. https:// doi.org/10.1016/S0925-8388(02)00790-9

30. I. D. Olekseyuk et al., Single crystal preparation and crystal structure of the $\mathrm{Cu}_{2} \mathrm{Zn} / \mathrm{Cd}, \mathrm{Hg} / \mathrm{SnSe}_{4}$ compounds, J. Alloys
Comp. 340 (2002) 141. https://doi.org/10.1016/ S0925-8388(02)00006-3

31. A.J. Mora, G.E. Delgado and P. Grima-Gallardo, Crystal structure of $\mathrm{CuFeInSe}_{3}$ from X-ray powder diffraction data, Phys. Stat. Solidi (a), 204 (2007) 547. https://doi.org/10. $1002 / \mathrm{pssa} .200622395$

32. G.E. Delgado, A.J. Mora, P. Grima-Gallardo and M. Quintero, Crystal structure of $\mathrm{CuFe} 2 \mathrm{InSe} 4$ from X-ray powder diffraction, J. Alloys Comp. 454 (2008) 306. https: / / doi .org/ $10.1016 / j . j a l l c o m .2006 .12 .057$

33. G. E. Delgado, P. Grima-Gallardo, J. A. Aitken, A. Cárdenas, and I. Brito, The new P-chalcopyrite compound $\mathrm{Cu}_{2} \mathrm{FeIn}_{2} \mathrm{Se}_{5}$; synthesis, thermal analysis, and crystal structure analysis by $\mathrm{X}$ ray powder diffraction, Rev. Mex. Fis. 67 (2021) 18. https: //doi.org/10.31349/RevMexFis.67.18

34. G. Krauss, V. Kraemer, A. Eifler, V. Riede and S. Wenger, Growth and characterization of $\mathrm{CdAl}_{2} \mathrm{~S}_{4}$ and $\mathrm{CdAl}_{2} \mathrm{Se}_{4}$ single crystals, Cryst. Res. Technol. 32 (1997) 223. https : / / doi . org/10.1002/crat.2170320202

35. H. Schwer and V. Kraemer, Structure refinement of $\mathrm{HgAl}_{2} \mathrm{Se}_{4}$, Z. Kristallogr. 194 (1991) 121. https://doi.org/10. 1524/zkri.1991.194.14.121.

36. G. E. Delgado, E. Quintero, R. Tovar, and M. Quintero, $\mathrm{X}$-ray powder diffraction study of the semiconducting alloy $\mathrm{Cu}_{2} \mathrm{Cd}_{0.5} \mathrm{Mn}_{0.5} \mathrm{GeSe}_{4}$, Cryst. Res. Technol. 39 (2004) 807. https://doi.org/10.1002/crat.200310257 